\title{
FAÇA O QUE VOCÊ AMA? O CONSUMO DO TRABALHO ADJETIVADO E A STARTUP 99JOBS
}

\section{Do what you love? The consumption of adjectival labour and startup 99Jobs}

\author{
Haz lo que amas? El consumo del trabajo adjetivado y la startup 99Jobs
}

Rafael Grohmann

Professor do Mestrado em Comunicação - Faculdade Cásper Líbero

rafael-ng@uol.com.br

\section{Resumo}

O artigo procura discutir o consumo simbólico do que chamamos de "trabalho adjetivado" (como criativo ou afetivo) - que faz parte de uma gramática hegemônica sobre o mundo do trabalho - considerando o trabalho como atividade humana e a partir do modo de produção capitalista. Compreende-se a instância da comunicação sobre o trabalho como reveladora das contradições dos processos comunicacionais e produtivos e busca-se entender, então, os discursos que circulam no site da startup 99Jobs, cujo slogan é "faça o que você ama".

Palavras-chave: Comunicação. Trabalho. Consumo

\begin{abstract}
The paper discusses the symbolic consumption of what we call "adjectival labour" (as creative or affective) - which is part of a hegemonic grammar of the world of work - considering the work as a human activity and from the capitalist mode of production. We understood the communication instance about labour as a revealing instance of the contradictions of communication and production processes and we seek to understand, then, the circulating discourses in the startup of the site 99Jobs, whose slogan is "do what you love."
\end{abstract}

Key words: Communication. Labour. Consumption.

\section{Resumen}

El artículo aborda el consumo simbólico de lo que llamamos "trabajo adjetivado" (como creativo o afectivo) - que es parte de una gramática hegemónica del mundo del trabajo teniendo en cuenta el trabajo como actividad humana y en modo de producción capitalista. Se entiende la instancia de comunicación en el trabajo como un ejemplo revelador de las contradicciones de los procesos de comunicación y de trabajo y buscamos entender, entonces, los discursos que circulan en el sitio 99Jobs, cuyo lema es "hacer lo que amas."

Palabras clave: Comunicación. Trabajo. Consumo 


\section{INTRODUÇÃO}

"Faça o que você ama": esse é o slogan da startup 99Jobs, uma plataforma - nas palavras da própria empresa - "de relacionamento com o trabalho" que ajuda na busca por “emprego dos sonhos”. Em sua página do Facebook, o slogan é: “temos amor”, com o desaparecimento da palavra "vagas". Não é de hoje que palavras como "amor" têm sido utilizadas como adjetivo nos discursos sobre o mundo do trabalho. Todavia, sua circulação nos processos comunicacionais e produtivos parece estar na ordem do dia.

Os discursos sobre o trabalho ajudam a sedimentar uma imagem sobre as próprias práticas produtivas, valorizando algumas competências e performances (EHRENBERG, 2010) em detrimento de outras. Com isso, há um consumo do trabalho considerado valorizado, como os próprios rankings de "melhores empresas para se trabalhar" ou matérias jornalísticas que mostram as empresas e os profissionais de sucesso. Esse consumo, então, se dá por meio de convocações dos dispositivos comunicacionais (AIDAR PRADO, 2013), inclusive nas mídias digitais, como chamamentos para os sujeitos se ajustarem às prescrições estabelecidas.

A partir disso, o objetivo desse artigo é discutir o que chamamos de "trabalho adjetivado" e a criação do valor do "afeto" a partir da subjetividade do trabalhador nos processos comunicacionais e produtivos, especialmente na produção de valor no capitalismo. Trazemos, então, como exemplo dessa discussão, uma análise do site 99Jobs, em que os trabalhadores produzem discursos sobre as empresas que trabalham. Aí a questão é: em um site cuja marca é "faça o que você ama", as pessoas discursam hegemonicamente sobre o amor e a felicidade (FREIRE FILHO, 2010) no mundo do trabalho? Então, procuramos mostrar as contradições nesses processos.

\section{COMUNICAÇÃO E MUDANÇAS NO MUNDO DO TRABALHO}

Podemos compreender o trabalho, em uma abordagem marxiana, como atividade humana e no modo de produção capitalista a partir da circulação de mercadorias e venda da força de trabalho (MARX; ENGELS, 2007; MARX, 2013). Trabalhar, então, de algum modo, sempre envolve, de modo dialético, criação e exploração, riqueza e miséria (ANTUNES, 2013), expressão e expropriação (HUWS, 2014). Ou seja, em certa medida, mostrar somente um dos lados é simplificar a realidade, mostrando-a de maneira não-contraditória. 
Porém, o que temos observado são discursos que acabam por obliterar a face da exploração, por considera-la parte de uma "gramática ultrapassada", quando não dizendo que o conceito de trabalho chegou ao fim. O que são louvados, então, são signos ligados à inovação, à criatividade e ao empreendedorismo (ROXO; GROHMANN, 2014; CASAQUI, 2014), como se estes não fizessem parte das condições materiais do próprio mundo do trabalho.

O que há são mudanças no próprio capitalismo e seus modos e discursos de justificação (BOLTANSKI; CHIAPELLO, 2009) capazes de mostrar que o mundo passa por uma "revolução criativa" enquanto essas transformações fazem parte do próprio motor do capitalismo. Como afirma Terry Eagleton (2012, p. 136),

hierarquias ao velho estilo talvez tenham cedido lugar em alguns setores da economia a formas de organização descentralizadas, baseadas em redes, em equipes, ricas em informação, camaradagem e informalidade, mas o capital continua concentrado em um número menor do que nunca de mãos, e as fileiras dos indigentes e carentes crescem a toda hora.

Essas mutações se relacionam com a intensificação da comunicação nos processos produtivos. Segundo Roseli Figaro (2008, p. 28), "as tecnologias e as linguagens do campo da comunicação são incorporadas ao novo modelo de organização da empresa desde a produção", sendo, assim, orientadas para a reprodução do capital. A interrelação entre processos comunicacionais e produtivos (WILLIAMS, 2011), então, se mostra central para a compreensão da sociedade atual e das mudanças no capitalismo.

A flexibilização é um elemento-chave dessa reorganização dos processos comunicacionais e produtivos. Boltanski e Chiapello (2009) mostram como, nas décadas de 1960 e 1970, havia um desejo de autonomia e liberdade por parte dos trabalhadores. Contudo, esse desejo foi reapropriado pelo capital, de forma a se tornar eminentemente yuppie aquilo que era hippie. Trata-se de um cenário de, como afirmam Dardot e Laval (2016), governamentalidade empresarial e neoliberal.

Desterritorialização da produção, terceirização e individualização das situações de trabalho fazem parte de um processo mais geral de precarização, que, de acordo com Marcelino (2011, p. 67), se relaciona à "inserção de novas tecnologias, [à] reorganização do espaço e [às] hierarquias das empresas, da necessidade da polivalência, da introdução de mecanismo de variação salarial”, além da incorporação de várias funções além da principal do 
trabalhador - um profissional "multitarefa", como mostramos em Grohmann (2013) a partir da exigência do jornalista se tornar polivalente e "convergente".

Nesse processo de precarização, Antunes (2013) elenca a erosão do trabalho contratado e regulamentado, a crescente degradação do trabalho imigrante e o "empreendedorismo", que, segundo o autor, "se configura cada vez mais como forma oculta de trabalho assalariado e múltipla as distintas formas de flexibilização de horário, salarial, funcional ou organizativa" (ANTUNES, 2013, p. 21).

Podemos afirmar, de certo modo, que esse "imperativo da flexibilidade" proporciona o que Alves (2011) chama de "captura" da subjetividade do trabalhador. "Captura", entre aspas, como o próprio autor ressalta, pois a subjetividade nunca pode ser inteiramente capturada considerando a ontologia do ser social (LUKÁCS, 2012). As convocações para se envolver nas atividades da "empresa", com participação e proatividade fazem parte desse processo, que Huws (2014) designa ser de "expressão" e “expropriação". Para ela, por um lado, "há um desejo, por parte dos trabalhadores individuais, de fazer algo significativo na vida, produzir uma marca no mundo, ser reconhecido, apreciado e respeitado" (HUWS, 2014, p. 124), mas no outro, há múltiplas formas de controle e de exploração. Para Antunes (2013, p. 14),

essa nova morfologia do trabalho (...). vem ampliando o universo do trabalho invisibilizado e potencializando novos mecanismos geradores de valor ainda que com aparência de não valor - a partir de novos e velhos mecanismos de intensificação (quando não de autoexploração) do trabalho.

Esses mecanismos convocatórios passam, necessariamente, por processos de comunicação, especialmente pela dimensão da "comunicação sobre o trabalho" (NOUROUDINE, 2002) composta por signos que produzem, constroem e circulam sentidos. Segundo Fígaro (2014, p. 64), “a atividade linguageira, nas relações de comunicação no mundo do trabalho, acompanham, comentam e produzem o trabalho real. Mostram também como são diferentes os lugares de enunciação da empresa (oficial) e do mundo do trabalho" ${ }^{1 "}$.

Dessa forma, a comunicação sobre o mundo do trabalho se mostra reveladora das contradições presentes nos processos produtivos: quem fala? A empresa? O trabalhador? Como sua posição de sujeito auxilia a modular sua fala em relação às atividades de trabalho?

\footnotetext{
${ }^{1}$ CF: REBECHI; FÍGARO, 2013.
} 
A partir das mudanças aqui enunciadas, há discursos sobre o mundo do trabalho com uma gramática que reitera ideias acerca de um trabalho "criativo", "inovador" e "com amor", em busca do "trabalho dos sonhos": é o que chamamos de consumo do trabalho adjetivado.

\title{
3 O CONSUMO DO TRABALHO ADJETIVADO
}

As narrativas comunicacionais constroem sentido sobre as atividades de trabalho, posicionando-as em corredores isotópicos meliorativos e pejorativos (BLIKSTEIN, 2003), com "modos de presença” (LANDOWSKI, 2002), de maneira a visibilizar algumas práticas em detrimento de outras, relegadas ao plano invisível, o que, de certa forma, ajuda a sedimentar a invisibilidade da desigualdade brasileira, nos termos de Jessé Souza (2006).

Essas narrativas se ajustam, em certa medida, às prescrições do "imperativo da flexibilidade" em decorrência das mudanças no capitalismo e ajudam a idealizar um "trabalho dos sonhos", que proporcione autonomia e liberdade. Considerando que o trabalho é uma importante mediação e que ajuda a sedimentar laços de pertencimento social (FIGARO, 2001; 2008), essas narrativas acabam por gerar um "consumo simbólico" desse "trabalho dos sonhos", tal qual Casaqui e Riegel (2009) mostram a partir do Google:

\begin{abstract}
O mundo do trabalho, identificado no cenário do Google com significações de criatividade, despojamento, modernidade e juventude, torna-se espetáculo que sublima o caráter competitivo e demais conotações negativas associadas a essa esfera de atuação humana. O trabalhador torna-se, nesse contexto comunicacional, o consumidor modelo do universo simbólico da marca utilizada simultaneamente como a corporificação do Google na sua estratégia de sedução pela criatividade dos possíveis consumidores. Trabalho e consumo, dessa forma, unem-se no mesmo campo simbólico, com a predominância na manifestação dos sentidos do consumo que mercadoriza a imagética do mundo do trabalho no contexto dos serviços tecnológicos de nosso tempo (CASAQUI; RIEGEL, 2009, p. 163).
\end{abstract}

Esse consumo simbólico de determinados tipos de trabalhos - a partir de signos como os de despojamento, criatividade e inovação - é o que chamamos de consumo do trabalho “adjetivado". Por que adjetivado? Dentro e fora do campo acadêmico, acaba-se por fetichizar conceitos (GUSMÃO, 2009), dotando-os de sentido e valor, o que acaba por se tornar também um consumo simbólico, algumas vezes acrítico.

Ora, o que chamamos, então, de "trabalho adjetivado"? Os adjetivos que acompanham a palavra "trabalho" de forma a mostrar um posicionamento meliorativo, como se fosse dito: 
"não estamos falando de um trabalho industrial", colocado como ultrapassado para o "presente flexível”. Então, pululam conceitos como os de trabalho criativo, classe criativa, trabalho cultural, economia (ou indústria) criativa, trabalho afetivo, capitalismo estético...

Assim, o termo proposto de "trabalho adjetivado" nada mais é que um conceito provocador a essas adjetivações, no sentido de questioná-las. Perguntamo-nos: a quem serve essa adjetivação? O trabalho, que é visto muitas vezes como "obrigação" ou algo "chato" pode ser positivado se for algo cool e descolado, com significações de modernidade (ou quaisquer outras adjetivações preferidas também para esse termo). Isto é, há a valorização de alguns trabalhos, considerados cool e valorizados no mercado em detrimento de outros.

Uma questão, então, que surge, ainda de forma inicial: será que há aí uma relação de classes? Com a valorização cega desses trabalhos ditos criativos, invisibilizam-se: a) por um lado, as próprias contradições e reais condições desses trabalhos considerados valorizados; $b$ ) por outro, a própria desigualdade social e o trabalho do "cibertariado" (HUWS, 2014; DYERWITHEFORD, 2015) e do precariado (STANDING, 2013; BRAGA, 2013).

De certa forma, essas adjetivações do trabalho, positivando certas circulações das relações de comunicação e trabalho em detrimento de outras favorecem a crença e a marca de uma "cultura hipster". Segundo Henke (2013), o termo se refere a grupos formados principalmente por jovens de classe média-alta que possuem uma marca identitária ligada ao "alternativo", mas que acaba por reforçar concepções hegemônicas na sociedade. "Um 'hipster' compartilha a aparência e os pontos de vista de reais inconformados, mas isso é motivado mais pelo desejo de criar uma imagem fashion de rebelde que por um genuíno radicalismo" (HENKE, 2013, p. 118).

Consideramos que o trabalho, em uma perspectiva marxiana, como atividade humana deve ser considerado em sua totalidade; não podendo, então, ser separado em "trabalhos criativos" ou "trabalhos mecânicos". Por exemplo, não é possível haver trabalho mental sem trabalho braçal, e vice-versa, o que mostra que essa divisão de "trabalho manual" e "intelectual" é equivocada, pois divide o ser social, como se existissem trabalhos que fossem "não-criativos" (como robôs), por exemplo. Raymond Williams (2000) também critica essa divisão:

o caso exemplar significativo é, atualmente, o dos impressores e outros trabalhadores 'manuais' na produção do jornal. Afirma-se com toda a

\footnotetext{
${ }^{2}$ Questão que também pretendemos aprofundar em outras ocasiões.
} 
segurança, dentro do que hoje se aceita sobre a sociedade de classes, que esses trabalhadores não têm absolutamente nenhuma relação legítima com o conteúdo da produção cultural (...). De um lado da divisão estão os que 'escrevem', do outro, os que 'imprimem'. O primeiro processo é considerado produção cultural, o último, meramente instrumental (WILLIAMS, 2000, p. 144)

Mente e corpo, pois, fazem parte da ontologia do ser social, e não podem ser separados, pois se tratam das condições materiais de vida. Segundo Eagleton (2012, p. 116), “o trabalho humano leva a natureza a ser essa extensão de nossos corpos, o que chamamos de civilização. Todas as instituições (...) são extensões do nosso corpo produtivo".

Entretanto, essa divisão é reproduzida mesmo no campo acadêmico. Quanto aos autores que se utilizam de termos como "trabalho adjetivado" ou até mesmo "capitalismo adjetivado", há aqueles que utilizam o conceito para louvá-los, com um tom otimista, como Florida (2010) em relação à classe criativa, como podemos observar nessa frase: "A classe criativa tem a dimensão, o poder e o talento necessários para desempenhar um papel importante na reformulação do mundo" (FLORIDA, 2010, p. XV). Outro que é, de alguma forma, otimista em relação a esses conceitos é Lipovetsky e Serroy (2015) com seu conceito de "capitalismo artista" ou "capitalismo estético". Ao defender a "estetização do mundo", acaba por defender como se o modo de produção capitalista hoje fosse mais "bonito" ou "suave" que antes.

Há também aqueles autores que, ao usar o termo adjetivado, pretendem antes criticar ou ironizar essas formas de trabalho que defendê-las. Assim, autores como McGuigan (2009), Ross (2009), Illouz (2011) e Huws (2014) entram nesse debate para afirmar que esse "trabalho criativo" ou "com afeto", na verdade, se trata de uma marca que não pode ser descolada da produção de valor no capitalismo.

Para McGuigan (2009), essa gramática se relaciona à mercantilização das relações humanas e a uma cultura empresarial ligada às prescrições neoliberais, com uma mais-valia extraída por meio do afeto (surplus love). Illouz (2011) segue na mesma direção ao mostrar a ascensão do homo sentimentalis no capitalismo, com a mobilização de recursos afetivos dos trabalhadores, principalmente da área de serviços, ocorrendo a hegemonia de narrativas terapêuticas ou de autorrealização.

Para Huws (2014), essa mobilização de recursos afetivos ajuda a legitimar sacrifícios no trabalho. A autora traz o seguinte exemplo: "é um trabalho que você tem que amar, por isso nós derramamos nossas tripas para fora". A autora, então, indaga: 
por que o desejo de classificar esses trabalhadores? E por que, particularmente, agora? Com a difusão simultânea das tecnologias digitais e da globalização comercial nos últimos anos do século $\mathrm{XX}$, esses trabalhadores assumiram uma nova importância como fontes de 'valor adicionado' ou 'propriedade intelectual' (PI). Na 'economia baseada no conhecimento' aspirada cada vez mais pelas políticas públicas, a criatividade é considerada como a matéria-prima essencial para o crescimento econômico (HUWS, 2014, p. 86)

Ross (2009), então, afirma que, no lugar desse ethos "debilitante" de criatividade ligado à mercantilização e à exploração do capital, "nós precisamos enxergar o trabalho criativo como um direito humano básico" (ROSS, 2009, p. 47). Quer dizer, no sentido marxiano que elencamos acima, como atividade humana capaz de criação.

Entretanto, essa questão deve ser sempre enxergada à luz da teoria do valor, o que Negri e Hardt (2005), por exemplo, não fazem ao louvar o "trabalho imaterial" e o "trabalho afetivo". Para eles, esse seria o "trabalho que produz ou manipula afetos com a sensação de bem-estar, tranquilidade, satisfação, excitação ou paixão" (NEGRI; HARDT, 2005, p. 149). Os autores ainda colocam sob a pecha de "serviço com sorriso" comissários de bordo e atendentes de lanchonete. Ora, trata-se de compreender apenas a fachada de seus trabalhos, desconsiderando-se a cruel realidade de exploração. Jappe (2006) também critica a falta da teoria do valor na obra de Negri e Hardt (2005): "a forma valor continua a existir, não porque as classes dominantes hajam decidido que assim devia ser, mas por se tratar de uma forma fetichista não percebida como tal pelos sujeitos" (JAPPE, 2006, p. 141).

A partir dessas questões, tentaremos observar como esse consumo do trabalho "adjetivado" aparece no site 99Jobs e nos discursos dos trabalhadores.

\section{O 99Jobs é Amor?}

O site 99Jobs é um dos muitos em circulação que, de alguma forma, ajudam a perpetuar o consumo do trabalho adjetivado. Assim como outras páginas como Glassdoor ${ }^{3}$ nos Estados Unidos, o 99Jobs é uma startup (outra palavra pertencente à gramática desse trabalho adjetivado) que se define como uma comunidade colaborativa para busca de empregos, especialmente um "emprego dos sonhos".

\footnotetext{
${ }^{3}$ Cujo slogan é "Get Hired. Love Your Job".
} 
Como já afirmado no início do artigo, o slogan é "Faça o que você ama". Em uma análise do ethos da startup, podemos observar que há uma preponderância do "trabalho com amor", tal qual afirmado por Negri e Hardt (2005), como um imaginário pós-capitalista e horizontal, que outras startups como AirBnB e Über ajudam a sedimentar, enquanto se trata de uma reiteração do próprio capitalismo em outras bases. Esse ethos fica evidente nos seguintes enunciados do 99Jobs: "apaixone-se: a 99Jobs é uma plataforma de relacionamento com o trabalho", "pesquise, desenvolva-se e ame essa ideia" e "uma empresa sem chefes".

Há também prescrições discursivas de como se chegar ao sucesso profissional, semelhantes às "narrativas de autoajuda" abordadas por Illouz (2011), porém sem a parte do sofrimento. Alguns exemplos: "olhe para dentro, não para fora"; "pergunte o que você faz bem"; "permita-se sonhar alto". Também são pontuados discursos que não seria bons de se falar por quem segue a startup, como em "amar é para pessoas, não para trabalho". Há, então, um discurso modalizador que visibiliza o amor e o afeto como motivadores primeiros de um trabalho, auxiliando no consumo de um trabalho ideal/ idealizado. Mas será que esse ethos que é o da organização - perpassa todos os discursos disponibilizados pelo site?

No 99Jobs, há uma relação de empresas, que são avaliadas por funcionários e exfuncionários, criando um ranking das melhores empresas para se trabalhar - performance que é valorizada nesse ethos. Essas avaliações se dão de forma "anônima" e aparecem no site somente as funções: "estagiário", "ex-funcionário", "gerente”, apesar de existirem pessoas que preferem se manter como um "funcionário anônimo". E essas avaliações se dão por meio de: a) notas dadas pelos trabalhadores de 1 a 5 para a empresa em questão; b) elenco de características da empresa que são "pontos positivos" e outras características que são "pontos a melhorar"4; c) discursos dos trabalhadores elencando, com suas próprias palavras, os prós e contras de se trabalhar naquele local.

Surge, então, uma questão: como garantir o anonimato dos discursos desses trabalhadores em um contexto de vigilância da força de trabalho ${ }^{5}$ nas mídias digitais?. Para Fuchs e Trottier (2013), a vigilância dos trabalhadores na Internet inclui: a) vigilância dos dados do perfil pessoal; b) vigilância do conteúdo produzido; c) vigilância da navegação e do comportamento de "cliques"; d) vigilância nas relações sociais e das redes; e) vigilância da comunicação. Em entrevista à Roseli Fígaro, Fuchs (2015, p. 71) afirma: “os capitalistas

\footnotetext{
${ }^{4}$ Faz parte também dessa gramática o de positivar condições de trabalho negativas, por isso não é um "ponto negativo", mas um "ponto a melhorar".

${ }^{5}$ Braverman (1987) já havia pontuado que a história do capitalismo é permeada pela história do controle da força do trabalho a partir da tecnologia e dos métodos de gestão do trabalho.
} 
exigem privacidade financeira, mas querem monitorar os trabalhadores, os indivíduos e os consumidores o tanto quanto podem". É necessário, pois, considerar os discursos disponibilizados no 99Jobs nesse contexto.

Nesses discursos dos trabalhadores, o ethos feliz e amoroso da startup pode dar lugar às contradições, revelando a riqueza do próprio mundo do trabalho, que, como já afirmado, é diferente do discurso da organização (REBECHI; FIGARO, 2013). Em pesquisa semelhante, Fuchs (2014) analisa o discurso dos trabalhadores do Google no Glassdoor. Nos enunciados, os trabalhadores revelam, por exemplo, noites dormidas no local de trabalho, as longas jornadas e a sobrecarga de trabalho, falta de vida social. Ou seja, ajudam a desmistificar o ethos da "empresa dos sonhos" analisado por Casaqui e Riegel (2009).

Trazemos, então, aqui, alguns enunciados do 99Jobs como exemplos dessas contradições reveladas na comunicação sobre o trabalho, que ajudam a tensionar o ethos da empresa. Contudo, diante das 2200 organizações presentes na startup no momento desta pesquisa, seria impossível tratar em um artigo de todos os discursos presentes. Então, trazemos aqui somente um exemplo, um indício, e escolhemos uma organização para tal: o banco Itaú. Poderia ser substituído por outra empresa, pois o importante é mostrar as contradições, mas o Itaú possui relevância no 99Jobs, tendo 3393 seguidores e 126 avaliações discursivas dos trabalhadores. Além disso, trata-se de uma instituição bancária, um importante braço do capitalismo e que possui, em sua publicização (CASAQUI, 2011), o ethos de uma empresa antenada, jovial e símbolo de mudanças - isto é, ajustada ao que estamos discutindo sobre o consumo do trabalho adjetivado. Casaqui (2014, p. 17) comenta um slogan recente do banco:

\footnotetext{
"O mundo muda. E o Itaú muda com você". Pelos encadeamentos lógicos do discurso, os produtos da corporação também têm o poder de fazer o mundo mudar (...). Fica nítida a disputa simbólica em torno de signos e significados que tem "valor social", mas que também se tornaram produtivos em termos de "valor comercial", pela ótica do mercado.
}

No 99Jobs, há enunciados que se ajustam ao ethos da empresa, como em "uma empresa que busca ser mais atual e jovem" e "empresa espetacular com pessoas maravilhosas e inesquecíveis". O orgulho de fazer parte da empresa e de "vestir a camisa" é um dos motivos dados por esses discursos ajustados e que se relacionam a como as atividades de comunicação e trabalho são requeridas a partir do toyotismo (FÍGARO, 2008), como uma convocação à participação, para se sentir parte de uma equipe, com orgulho. 
O enunciado "A empresa que me ensinou a ter brilho nos olhos e amor à camisa" dá um exemplo disso e mostra também interdiscursividade com a performance de uma competição esportiva para ser um vencedor, como mostra também Ehrenberg (2010, p. 22): “a referência ao esporte e à aventura está, na verdade, cada vez mais presente em diversas publicações profissionais ou semiprofissionais". Outro exemplo pode ser visto em: "sempre tenho a impressão que o Itaú é visionário. Sinto muito orgulho em fazer parte de uma empresa tão inovadora". O "afeto" que tem pela empresa se relaciona à inovação, parte da mesma gramática do consumo do trabalho adjetivado.

Se os enunciados acima acabam por reforçar o ethos do Itaú e do próprio 99Jobs, a maior parte dos enunciados revela as contradições vividas no mundo do trabalho. Por exemplo: "a empresa é ótima em questões de salário e benefícios, mas na questão de gestão é horrível. Fui dispensado da empresa após 3 dias que contei ao meu gestor que era homossexual e que estava enfrentando dificuldades a respeito disso"; "difícil crescimento. Ambiente hostil e competitivo"; "é muito bonito para quem ouve, e muito diferente para quem faz".

Isto é, trata-se do trabalho enunciado do ponto de vista dos trabalhadores e não da empresa, e há resistência ao ethos hegemônico circulante. Um trabalhador chega a enunciar: "poderia ser melhor se aplicasse na prática o que divulga na mídia". Ou seja, o consumo simbólico do trabalho pelo ethos da empresa não se realiza totalmente na prática. O próximo enunciado também nos dá pistas sobre isso:

Faltam incentivos para a inovação, a melhoria de processos e a diminuição da burocracia. A empresa tem uma imagem de inovação para o mercado, mas na prática isso não acontece, pois é tudo muito engessado e burocrático, matando qualquer processo criativo. Não há nenhuma preocupação com qualidade de vida e com a vida pessoal dos funcionários, o que importa é entregar a meta no fim do ano. Não há NENHUMA flexibilidade com relação ao horário de trabalho, não importa se você trabalhou 16 horas no dia anterior, no dia seguinte precisa cumprir sua jornada.

O enunciado não mostra sinais de um imaginário pós-capitalista ou de um trabalho afetivo ou "com sorriso". Pelo contrário: ressalta a não-preocupação com qualidade de vida e nem com a flexibilidade - mesmo em um universo de prescrições em prol do trabalho flexível. A atividade concreta de trabalho nem sempre é tão flexível quanto seu discurso (Bernardo, 2009). As longas jornadas de trabalho são enfatizadas no enunciado do trabalhador, bem como a preocupação com as metas, revelando a precarização do trabalho. $\mathrm{O}$ 
mais interessante é a negação da "inovação" e da "criatividade" como parte de seu processo produtivo: "faltam incentivos para a inovação", "matando qualquer processo criativo".

\section{CONSIDERAÇÕES FINAIS}

$\mathrm{O}$ artigo procurou trazer algumas reflexões sobre processos comunicacionais e produtivos em relação ao que chamamos de consumo do trabalho adjetivado, trazendo como exemplo a startup 99 Jobs, sem a pretensão de esgotar o assunto. Enquanto, por um lado, há a construção de um ethos de criatividade, inovação e afetividade (até por alguns autores do campo acadêmico), em alguma medida, os discursos sobre o trabalho por parte dos trabalhadores na plataforma ajudam a revelar outros lugares de fala que não os das organizações, com contradições e "senões" dessas prescrições, ajudando a tensioná-las, em processos contraditórios de ajustamentos e resistências.

A nosso ver, não é possível compreender corretamente os processos comunicacionais e produtivos de uma perspectiva idealista e que desconsidere o trabalho tanto como atividade humana quanto a partir do modo de produção capitalista e sua produção de valor. Desse modo, evitamos cair em armadilhas louvadoras das "novidades" advindas do "belo, fofo e amoroso mundo das startups" e a gramática que elas carregam consigo.

\section{REFERÊNCIAS}

AIDAR PRADO, José Luiz. Convocações Biopolíticas dos Dispositivos Comunicacionais. São Paulo: Educ, 2013.

ALVES, Giovanni. Trabalho e Subjetividade. São Paulo: Boitempo, 2011

ANTUNES, Ricardo. A nova morfologia do trabalho e suas principais tendências. In: ANTUNES, Ricardo (org.). Riqueza e Miséria do Trabalho no Brasil II. São Paulo: Boitempo, 2013, p. 13-28.

BERNARDO, Marcia Espanhol. Trabalho Duro, Discurso Flexível: uma análise das contradições do toyotismo a partir da vivência de trabalhadores. São Paulo: Expressão Popular, 2009

BLIKSTEIN, Izidoro. Kaspar Hauser ou a Fabricação da Realidade. São Paulo: Cultrix, 2003.

BOltanski, Luc; CHIAPEllo, Ève. O Novo Espírito do Capitalismo. São Paulo: Martins Fontes, 2009

BRAGA, Ruy. A Política do Precariado. São Paulo: Boitempo, 2013.

BRAVERMAN, Harry. Trabalho e Capital Monopolista: a degradação do trabalho no século XX. Rio de Janeiro: Zahar, 1987. 
CASAQUI, Vander. Por uma teoria da publicização: transformações no processo publicitário. Significação. São Paulo, n. 36, 2011, p. 131-151.

CASAQUI, Vander. A invenção de um país de empreendedores sociais: 'Imagina na Copa' e seu projeto de Brasil. In: Encontro Anual da Associação Nacional dos Programas de Pós-Graduação em Comunicação - Compós, 2014, Belém/PA. Anais da Compós 2014. Belém: Compós, 2014

CASAQUI, Vander; RIEGEL, Viviane. Google e o consumo simbólico do trabalho criativo. Comunicação, Mídia e Consumo. São Paulo, v. 6, n. 17, p. 161-180, nov. 2009.

DARDOT, Pierre; LAVAL, Christian. A Nova Razão do Mundo. São Paulo: Boitempo, 2016.

DYER-WITHEFORD, Nick. Cyber-Proletariat: global labour in the digital vortex. London: Pluto Press, 2015.

EAGLETON, Terry. Marx estava certo. Rio de Janeiro: Nova Fronteira, 2012.

EHRENBERG, Alain. O Culto da Performance: da aventura empreendedora à depressão nervosa. Aparecida/SP: Ideias e Letras, 2010

FIGARO, Roseli. Comunicação e Trabalho: estudo de recepção - o mundo do trabalho como mediação da comunicação. São Paulo: Anita/Fapesp, 2001.

FIGARO, Roseli. Relações de Comunicação no Mundo do Trabalho. São Paulo: Annablume, 2008.

FIGARO, Roseli. O campo da comunicação e a atividade linguageira no mundo do trabalho. Revista Chasqui. N. 126, outubro/2014

FLORIDA, Richard. A Ascensão da Classe Criativa. Porto Alegre: L\&PM, 2011.

FREIRE FILHO, João (org.). Ser Feliz Hoje: reflexões sobre o imperativo da felicidade. Rio de Janeiro: Ed. FGV, 2010.

FUCHS, Christian; TROTTIER, Daniel. The Internet as surveilled workplayplace and factory. In: GUTWIRTH, Serge et alli (org.). European Data Protection: coming of age. Dordrecht: Springer, 2013, p. 33-57.

FUCHS, Christian. Social Media: a critical introduction. London: Routledge, 2014.

FUCHS, Christian. Atualidade de Marx para entender o trabalho na comunicação e na cultura. Entrevista a Roseli Figaro. Revista Eptic, v. 17, n.1, jan-abr. 2015.

GROHMANN, Rafael. O Trabalho do Jornalista como Sintoma da Lógica dos Conglomerados. Revista Alterjor. V. 02, n. 08, jul/dez. 2013, p. 1-15.

GUSMÃO, Luís de. O Fetichismo do Conceito: limites do conhecimento teórico da investigação social. Rio de Janeiro: Topbooks, 2012.

HENKE, Kelsey. Postmodern Authenticity and the Hipster Identity. Forbes \& Fifty. N. 2, v. 3, p. $115-129,2013$

HUWS, Ursula. Labor in the Global Digital Economy: the cybertariat comes of age. New York: Monthly Review Press, 2014. 
ILLOUZ, Eva. O Amor nos Tempos de Capitalismo. Rio de Janeiro: Zahar, 2011

JAPPE, Anselm. As Aventuras da Mercadoria. Lisboa: Antígona, 2006.

LANDOWSKI, Eric. Presenças do Outro: ensaios de sociossemiótica. São Paulo: Ed. Perspectiva, 2002 .

LIPOVETSKY, Gilles; SERROY, Jean. A Estetização do Mundo: viver na era do capitalismo artista. São Paulo: Cia. das Letras, 2015

LUKÁCS, György. Para uma Ontologia do Ser Social I. São Paulo: Boitempo, 2012.

MARCELINO, Paula. As Palavras e as Coisas: uma nota sobre a terminologia dos estudos contemporâneos de trabalho. Mediações. Londrina, v. 16, n. 1, p. 55-70, 2011.

MARX, Karl. O Capital: crítica da economia política - Livro I: o processo de produção do capital. São Paulo: Boitempo, 2013.

MARX, Karl; ENGELS, Friedrich. A Ideologia Alemã: São Paulo: Boitempo, 2007.

McGUIGAN, Jim. Cool Capitalism. New York: Pluto Press, 2009.

NEGRI, Antonio; HARDT, Michael. Multidão. Rio de Janeiro: Record, 2005.

NOUROUDINE, Abdallah. A linguagem: dispositivo revelador da complexidade do trabalho. In:

SOUZA-E-SILVA, Maria Cecília; FAÏTA, Daniel. Linguagem e Trabalho: construção de objetos de análise no Brasil e na França. São Paulo: Cortez, 2002.

REBECHI, Claudia; FIGARO, Roseli. A comunicação no mundo do trabalho e a comunicação da organização: duas dimensões distintas. ANIMUS: revista interamericana de comunicação midiática. Santa Maria, v. 12, n. 24, p. 1-23, 2013.

ROSS, Andrew. Nice Work If You Can Get It: life and labor in precarious times. New York: New York University Press, 2009.

ROXO, Michelle; GROHMANN, Rafael. Sentidos do Empreendedorismo no Campo Profissional Jornalístico. 4o Congresso Internacional de Comunicação e Consumo - Comunicon. Anais do Comunicon. São Paulo: ESPM, 2014.

SOUZA, Jessé. A Invisibilidade da Desigualdade Brasileira. Belo Horizonte: Ed. UFMG, 2006.

STANDING, Guy. O Precariado: a nova classe perigosa. Belo Horizonte: Autêntica, 2013

WILLIAMS, Raymond. Cultura. São Paulo: Paz e Terra, 2000.

WILLIAMS, Raymond. Cultura e Materialismo. São Paulo: Ed. Unesp, 2011. 
Professor do Mestrado em Comunicação da Faculdade Cásper Líbero e professor contratado III da Escola de Comunicações e Artes da Universidade de São Paulo (ECA-USP). Doutor e Mestre em

Ciências da Comunicação da Universidade de São Paulo (USP). Realiza pós-doutoramento no PPGCOM-UFRJ sob a supervisão do professor Muniz Sodré. Editor associado da revista E-Compós.

Vice-Coordenador do GP de Teorias da Comunicação da INTERCOM. Foi criador, coordenador e professor do Mestrado Profissional em Jornalismo do FIAM-FAAM - Centro Universitário. Integrante do Grupo de Pesquisa "Teorias e Processos da Comunicação" (Cásper Líbero) e do Centro de Pesquisa em Comunicação e Trabalho (CPCT - ECA/USP). Possui graduação em Ciências Sociais pela Universidade Federal de Juiz de Fora - UFJF (2009). Têm experiência na área de Comunicação, atuando principalmente nos seguintes temas: teorias da comunicação, estudos de recepção, trabalho dos jornalistas, comunicação e trabalho.

Esta obra está licenciada sob uma Licença Creative Commons. 